Article

\title{
Synthesis of a Novel $\alpha$-Glucosyl Ginsenoside F1 by Cyclodextrin Glucanotransferase and Its In Vitro Cosmetic Applications
}

\author{
Seong Soo Moon ${ }^{1,+}$, Hye Jin Lee ${ }^{1,+}$, Ramya Mathiyalagan ${ }^{2}$, Yu Jin Kim ${ }^{1}$, Dong Uk Yang ${ }^{1,3}$, \\ Dae Young Lee ${ }^{4}{ }^{(\mathbb{C}}$, Jin Woo Min ${ }^{1}$, Zuly Jimenez ${ }^{2}$ and Deok Chun Yang ${ }^{1,2, *}$ \\ 1 Department of Oriental Medicinal Biotechnology, College of Life Science, Kyung Hee University, \\ 1 Seocheon-dong, Giheung-gu, Yongin-si, Gyeonggi-do 17104, Korea; ssm8656@hanmail.net (S.S.M.); \\ serendipity27@nate.com (H.J.L.); yujinkim@khu.ac.kr (Y.J.K.); rudckfeo23@naver.com (D.U.Y.); \\ hero304@khu.ac.kr (J.W.M.) \\ 2 Graduate School of Biotechnology, College of Life Science, Kyung Hee University, 1 Seocheon-dong, \\ Giheung-gu, Yongin-si, Gyeonggi-do 17104, Korea; ramyabinfo@gmail.com (R.M.); zejp78@gmail.com (Z.J.) \\ 3 K-gen (corp), 218, Gajeong-ro, Yuseong-gu, Daejeon 34129, Korea \\ 4 Department of Herbal Crop Research, National Institute of Horticultural and Herbal Science, RDA, \\ Eumseong 27709, Korea; dylee0809@gmail.com \\ * Correspondence: dcyang@khu.ac.kr; Tel.: +82-31-201-2100; Fax: +82-31-205-2688 \\ + These authors contributed equally to this work.
}

Received: 28 August 2018; Accepted: 30 October 2018; Published: 10 November 2018

\begin{abstract}
Ginsenosides from Panax ginseng (Korean ginseng) are unique triterpenoidal saponins that are considered to be responsible for most of the pharmacological activities of $P$. ginseng. However, the various linkage positions cause different pharmacological activities. In this context, we aimed to synthesize new derivatives of ginsenosides with unusual linkages that show enhanced pharmacological activities. Novel $\alpha$-glycosylated derivatives of ginsenoside F1 were synthesized from transglycosylation reactions of dextrin (sugar donor) and ginsenoside F1 (acceptor) by the successive actions of Toruzyme ${ }^{\circledR} 3.0 \mathrm{~L}$, a cyclodextrin glucanotransferase. One of the resultant products was isolated and identified as (20S)-3 $3,6 \alpha, 12 \beta$-trihydroxydammar-24ene(20-O- $\beta$ - $D$-glucopyranosyl-( $1 \rightarrow 2)$ - $\alpha$ - $D$-glucopyranoside) by various spectroscopic characterization techniques of fast atom bombardment-mass spectrometry (FAB-MS), infrared spectroscopy (IR), proton-nuclear magnetic resonance $\left({ }^{1} \mathrm{H}-\mathrm{NMR}\right),{ }^{13} \mathrm{C}-\mathrm{NMR}$, gradient heteronuclear single quantum coherence (gHSQC), and gradient heteronuclear multiple bond coherence (gHMBC). As expected, the novel $\alpha$-glycosylated ginsenoside F1 (G1-F1) exhibited increased solubility, lower cytotoxicity toward human dermal fibroblast cells (HDF), and higher tyrosinase activity and ultraviolet A (UVA)-induced inhibitory activity against matrix metalloproteinase-1 (MMP-1) than ginsenoside F1. Since F1 has been reported as an antiaging and antioxidant agent, the enhanced efficacies of the novel $\alpha$-glycosylated ginsenoside F1 suggest that it might be useful in cosmetic applications after screening.
\end{abstract}

Keywords: cyclodextrin glycosyltransferase; cyclodextrin glycosyltransferase (CGTase); ginsenoside F1; $\alpha$-glucosyl ginsenoside F1

\section{Introduction}

Ginseng saponins, referred to as ginsenosides, are one of the major bioactive substances of Panax ginseng Meyer, a commonly used traditional herbal medicine in Korea, China, and Japan. Ginsenosides have been reported to have antifatigue and antioxidant activities, improve brain function, enhance stamina, and regulate blood circulation with approval from the Korea Food and Drug 
Administration (KFDA), in addition to various other pharmacological activities including anticancer [1,2], anti-inflammation [3], and antidiabetes [1,4] functions. These various pharmacological activities of ginsenosides typically depend on the types of sugar moieties and the position and linkage of their attachment [4,5]. More than 289 distinct saponins had been identified from different Panax sp. up to 2012 [6], and these compounds show different biological activities based on structural differences [3].

Ginsenosides are mainly classified as protopanaxadiol-type (PPD), protopanaxatriol-type (PPT), and oleanane-type saponins and further grouped into major and minor saponins based on the position and linkages of sugar moieties. The minor saponins, which are ginsenoside metabolites, are responsible for most of the pharmacological activities of ginseng which include ginsenoside F1, Rh1, compound K, and Rh2 [7]. These ginsenosides are mainly absorbed into systemic circulation [8]. Ginsenoside F1 is a minor saponin from the leaf of $P$. ginseng that was reported to have skin whitening activity [9], modulate skin diseases [10], and function as an antiaging and antioxidant agent [11], suggesting that it might be a candidate for cosmetic applications.

Synthesis of novel and diversified compounds is a way to extend the efficacy of natural products. Such diversity can be generated by biosynthetic reactions such as glucosylation [12,13]. Especially, enzymatic glycosylation provides more regioselectiveness than conventional chemical synthesis [14]. A number of reports have suggested that transglycosylation by enzymes can be used to improve physiochemical functions such as taste, solubility in water, and oxidative stability of numerous active substances $[15,16]$. Among these enzymes, cyclodextrin glycosyltransferase (CGTase, 1,4- $\alpha$-D-glucan: 1,4- $\alpha$-D-glycopyranosyltransferase, cyclizing, EC 2.4.1.19) [17] has been reported to accelerate reactions between natural products and starch hydrolysate or $\beta$-cyclodextrin to produce glucosylated modifications of natural compounds such as hesperidin, glycosylglycerol [14,16] rutin [18], and steroidal saponins [19].

Although the beta isomer was prominent, the alpha isomer has attracted much attention in recent years. The increased solubility of hesperidin $[16,18]$ and decreased bitterness of glycosylated stevioside [15] by CGTase was reported. Other studies reported the mild sweet taste with no odor, no tongue-pricking, and increased stability of $O-\alpha$-glucosylthiamin compared with thiamin hydrochloride [20] and the powerful skin whitening activity of alpha arbutin [21] compared with beta arbutin [22] as a result of glycosylation by CGTase.

In this study, we aimed to synthesize the unusual alpha glycosylated ginsenoside F1 by a reaction involving ginsenoside F1, dextrin, and CGTase. One of the resultant novel compounds was purified, and the structure was elucidated by various nuclear magnetic resonance (NMR) spectra and Fourier-transform infrared spectroscopy (FTIR). We also evaluated the cytotoxicity and protective effect of $\alpha$-glycosylated ginsenoside $\mathrm{F} 1$ against ultraviolet (UV) damage by measuring matrix metalloproteinase-1 (MMP-1) expression in human dermal fibroblast cells. In addition, the in vitro antityrosinase activity of $\alpha$-glycosylated ginsenoside F1 was evaluated against mushroom tyrosinase.

\section{Materials and Methods}

\subsection{Materials}

Ginsenosides compound K (CK), Rh2, Rh1, F1, aglycone PPD (aPPD), and aglycone PPT (aPPT) were obtained from the laboratory of Hanbangbio, Kyung Hee University, South Korea. Toruzyme 3.0L (the crude enzyme of CGTase) obtained from Novozymes, China, was extracted from Thermoanaerobacter sp. Dextrin was supplied by Fluka Chemie AG (Buchs, Switzerland), and all the other chemicals used were of analytical grade and from commercial sources.

\subsection{Biotransformation}

The preliminary screening of glycosylation was carried out as the method of Wang et al., 2010 [19]. Different ginsenosides, CK (1.6 mM, 1 eq), Rh2 (1.6 mM, 1 eq), Rh1 (1.56 mM,1 eq), F1 (1.56 mM, $1 \mathrm{eq}), \mathrm{aPPD}(2.17 \mathrm{mM})$, and aPPT $(2.09 \mathrm{mM})$ together with the sugar donor dextrin $(9.9 \mathrm{mM}, 6 \mathrm{eq}$, 
10-15 units of glucose) were dissolved in $20 \mathrm{mM}$ sodium phosphate buffer (1 mL, pH 7.0). Next, $25 \mu \mathrm{L}$ of Toruzyme ${ }^{\circledR} 3.0 \mathrm{~L}$ with initial activity of $3.0 \mathrm{KNU}$ (kilo novo units)/g [17] was added to the reaction mixture and reacted at $50{ }^{\circ} \mathrm{C}$ for $2 \mathrm{~h}$. and kept in boiling water for $5 \mathrm{~min}$ to inactivate the enzyme. The mixture was extracted three times with an equal volume of $n$-butanol, and the $n$-butanol layer was washed twice with distilled water to remove excess dextrin, dried in a rotary evaporator under vacuum [19], and dissolved in methanol for thin-layer chromatography (TLC).

\subsection{Glycosylation of Ginsenoside F1}

For further experimental analysis, F1 was used as a substrate. The effects of different concentrations of dextrin $(0-7 \mathrm{mg})$ and Toruzyme ${ }^{\circledR}(5-30 \mu \mathrm{L})$ and different reaction durations $(0.5-3 \mathrm{~h})$ on specificity of F1 glycosylation were examined using the procedure described above. For purification of glycosylated F1, F1 (500 mg, $1.56 \mathrm{mM}, 1 \mathrm{eq})$ and dextrin $(2 \mathrm{~g}, 7.92 \mathrm{mM}, 5 \mathrm{eq})$ were dissolved in $500 \mathrm{~mL}$ of $20 \mathrm{mM}$ sodium phosphate buffer and then treated with $15 \mathrm{~mL}$ of Toruzyme ${ }^{\circledR} 3.0 \mathrm{~L}$.

\subsection{Identification of Glycosylated Ginsenoside F1}

Semiqualitative screening of the glycosylated products was carried out by TLC and high-performance liquid chromatography (HPLC) was carried out by Ramya et al., 2015 and Quan et al., 2012 [13,23] with slight modifications. TLC was performed with silica gel plates (60 F254, Merck, Darmstadt, Germany) using the developing solvent $\mathrm{CHCl}_{3}: \mathrm{CH}_{3} \mathrm{OH}: \mathrm{H}_{2} \mathrm{O}(65: 35: 10, v / v$, lower phase). The TLC plates were dried, dipped in $10 \% \mathrm{H}_{2} \mathrm{SO}_{4}$, and air dried with heating at 110 to $120{ }^{\circ} \mathrm{C}$. The HPLC analysis was carried out on an Agilent 1260 series with a $C_{18}(250 \times 4.6 \mathrm{~mm}$, ID $5 \mu \mathrm{m})$ column using distilled water as solvent $\mathrm{A}$ and acetonitrile as solvent $\mathrm{B}$ mobile phases. The following gradient was used: A:B ratios of 80.5:19.5 for 0-29 $\mathrm{min}, 70: 30$ for 29-36 min, 68:32 for 36-45 min, 66:34 for 45-47 $\mathrm{min}, 64.5: 35.5$ for 47-49 $\mathrm{min}, 0: 100$ for 49-61 $\mathrm{min}$, and 80.5:19.5 for 61-66 min with a flow rate of $1.6 \mathrm{~mL} / \mathrm{min}$. The sample was detected at a wavelength of $203 \mathrm{~nm}$.

\subsection{Nuclear Magnetic Resonance Analysis}

Structural elucidation of the new compound by NMR spectra $\left({ }^{1} \mathrm{H}\right.$ NMR, ${ }^{13} \mathrm{C}$ NMR, gHSQC (heteronuclear single quantum correlation) and heteronuclear multiple bond correlation (gHMBC)) were performed using a Varian Unity INOVA AS 400 FT-NMR spectrometer (Varian, Palo Alto, CA, USA), and chemical shifts were expressed in $\delta(\mathrm{ppm})$, with tetramethylsilane (TMS) used as an internal standard. The dimethyl sulfoxide- $\mathrm{d}_{6}\left(\mathrm{DMSO}-\mathrm{d}_{6}\right)$ was used as a solvent. Melting points were obtained using a Fisher-John's melting point apparatus. Optical rotations were measured on a JASCO P-1010 digital polarimeter. Infrared spectra were obtained on a Perkin Elmer Spectrum One FTIR spectrometer (Perkin-Elmer, Walthanm, MA, USA). High resolution fast-atom bombardment mass spectrometry (HR-FAB/MS) were recorded using a JEOL JMS-700 (JEOL, Tokyo, Japan) mass spectrometer.

\subsection{Cell Lines and Cell Culture}

Human dermal fibroblasts (HDF) were purchased from the Korean Cell Line Bank (Seoul, Korea). The cells were grown in Dulbecco's modified essential media (DMEM) supplemented with 10\% fetal bovine serum (FBS) and $1 \%$ penicillin-streptomycin at $37^{\circ} \mathrm{C}$ in a humidified atmosphere containing $95 \%$ air and $5 \% \mathrm{CO}_{2}$.

\subsubsection{Ultraviolet Irradiation and Sample Treatment}

A high-pressure metal halide lamp (UVASUN 3000, Mutzhas, Munich, Germany) emitting wavelengths in the range of 340 to $450 \mathrm{~nm}$ was used as a UV source. Human dermal fibroblasts cells were seeded at $4 \times 10$ cell/dish in $60-\mathrm{mm}$ culture dishes for $24 \mathrm{~h}$. Prior to UV irradiation, cells were washed twice with phosphate buffer saline (PBS), and the medium was replaced with $1 \mathrm{~mL}$ of PBS. The incident dose at the surface of the cells was $66 \mathrm{~mW} / \mathrm{s}$. The spectral distribution of the 
UVASUN 3000 source was determined with a Beckman UV 5270 spectrophotometer (Beckman, Munich, Germany, FRG).

\subsubsection{Cytotoxicity Assay}

Human dermal fibroblasts cells were cultured at a density of $1 \times 10^{4}$ cells/well in 96-well flat-bottomed plates in a $5 \% \mathrm{CO}_{2}$ humidified atmosphere at $37^{\circ} \mathrm{C}$. After $24 \mathrm{~h}$ of culture, the medium was exchanged with medium containing different concentrations of ginsenoside F1 (F1) and $\alpha$-glycosylated ginsenoside F1 (Glycosylated F1), and the cells were incubated for a further $24 \mathrm{~h}$. Cell viability was determined by the 3-(4,5-dimethylthiazol-2-yl)-2,5-diphenyltetrazolium bromide (MTT) assay [24] with slight modification. Briefly, $10 \mu \mathrm{L}$ of MTT solution $(5 \mathrm{mg} / \mathrm{mL})$ was added to each well and incubated for $4 \mathrm{~h}$. After removal of MTT, the cells were lysed with $100 \mu \mathrm{L} \mathrm{DMSO}$, and absorbance was measured at $570 \mathrm{~nm}$ using a microplate reader (Bio-Tek Instruments, Winooski, VT, USA).

\subsubsection{In Vitro Tyrosinase Inhibition Activity}

Tyrosinase from Agricus bisporus (mushroom) was purchased from Sigma Chemicals Co. (St Louis, MO, USA). Inhibition of tyrosinase activity was measured as previously described [22]. L-DOPA (3-(3,4-dihydroxyphenyl)-L-alanine, 0.83 or $3.3 \mathrm{mM}$ ) was used as the substrate, and 600 units of tyrosinase was added in the presence or absence of F1, glycosylated F1, or arbutin. The absorbance was measured at $475 \mathrm{~nm}$ in a microplate reader (Bio-Tek Instruments, Winooski, VT, USA).

\subsubsection{Assay for Inhibition of Matrix Metalloproteinase-1 Expression}

Matrix metalloproteinase-1 (MMP-1) level was quantified using a sandwich ELISA Quantikine total human MMP-1 kit (R\&D Systems Inc., Minneapolis, MN, USA) After UV irradiation, HDF cells were cultured in DMEM with F1, and glycosylated F1, or ((-)-cis-3, $3^{\prime}, 4^{\prime}, 5,5^{\prime}, 7-$ hexahydroxy-flavane-3-gallate) (EGCG) as a positive control. The culture supernatants were harvested, and MMP-1 was measured according to the manufacturer's instructions. Absorbance was measured at $490 \mathrm{~nm}$ in a microplate reader microplate reader (Bio-Tek Instruments, Winooski, VT, USA).

\section{Results and Discussion}

\subsection{Biotransformation of Minor Ginsenosides by Cyclodextrin glycosyltransferase (CGTase)}

Among the major ginsenosides, $\mathrm{Rb} 1, \mathrm{Rc}, \mathrm{Re}$, and $\mathrm{Rg} 1$ have already been used as substrates for the synthesis of series of new $\alpha$-glycosylginsenosides through transglycosylation $[13,25,26]$. However, after oral administration, the major ginsenosides were converted into minor ginsenosides by intestinal microflora. Therefore, we used minor ginsenosides CK, Rh2, F1, Rh1, aPPD, and aPPT as acceptors with dextrin as a sugar donor during CGTase enzyme transglycosylation. As a result, CK, Rh2, $\mathrm{F} 1$, and Rh1 yielded new transglycosylated compounds with different retention factor $\left(\mathrm{R}_{\mathrm{f}}\right)$ values compared with known ginsenoside standards (Figure S1). Among these, PPT type ginsenosides Rh1 and F1 showed more glycosylated products, possibly due to the glucose attached to $\alpha-\mathrm{OH}$ at $\mathrm{C}-6$ and another $-\mathrm{OH}$ at $\mathrm{C}-20$ of the dammerendiol steroidal aglycone. We chose F1 for further studies because of the distinct separation of glycosylated products in addition to its previous reported application in cosmetics and skin care. PPD and PPT aglycone did not generate glycosylated products, indicating that sugar molecules are primarily involved in transglycosylation.

\subsection{Specificity of Transglycosylation of Ginsenoside F1}

Even though the effects of various factors on transglycosylation by Toruzyme were already reported $[19,27]$, this should be validated for the effective synthesis of new compounds. Therefore, the effects of different concentrations of dextrin and CGTase (Toruzyme) on the degree of glycosylation were investigated by HPLC. As shown in Figure S2a, the 5:1 w/w ratio of dextrin: F1 showed the highest yield. There was no significant difference for greater than five volumes, and it was difficult 
to separate saponin after biotransformation due to the combined extraction of sugar with saponin in the recovery process. In addition, increasing the amount of enzyme rapidly increased the yield up to $20 \mu \mathrm{L}$ of enzyme with $1 \mathrm{mg}$ of F1 and $5 \mathrm{mg}$ of dextrin, as determined by HPLC (Figure S2b).

\subsection{Transglycosylation Analysis of Ginsenoside F1}

The glycosylation of F1 with dextrin and CGTase for different time durations yielded several new spots that appeared below F1 on TLC (Figure S3). The reaction products were washed several times with water to remove the unreacted excess sugar molecules. The six new spots (G1-F1, G2-F1, G3-F1, G4-F1, G5-F1, and G6-F1) under ginsenoside F1 on TLC (Figure 1a) and the corresponding peaks (G1-F1, G2-F1, G3-F1, G4-F1, G5-F1, and G6-F1), other than ginsenoside F1 on HPLC analysis (Figure $1 b)$, were considered new glycosylated products from F1. G1-F1 $\left(\mathrm{R}_{\mathrm{f}}=0.53\right)$ on TLC was isolated as a pure form by silica gel chromatography and elution with $\mathrm{CHCl}_{3} / \mathrm{CH}_{3} \mathrm{OH}(9: 1)$. The yield of compound G1-F1 was $12 \%(74 \mathrm{mg})$ and the structure was identified by ${ }^{1} \mathrm{H}-\mathrm{NMR},{ }^{13} \mathrm{C}-\mathrm{NMR}$, and two-dimensional (2D) NMR and by correlations with the HSQC and HMBC spectra. The low percentage of yield is due to the formation of other products (G2-F1, G3F1, G4-F1, G5-F1, and G6-F1).

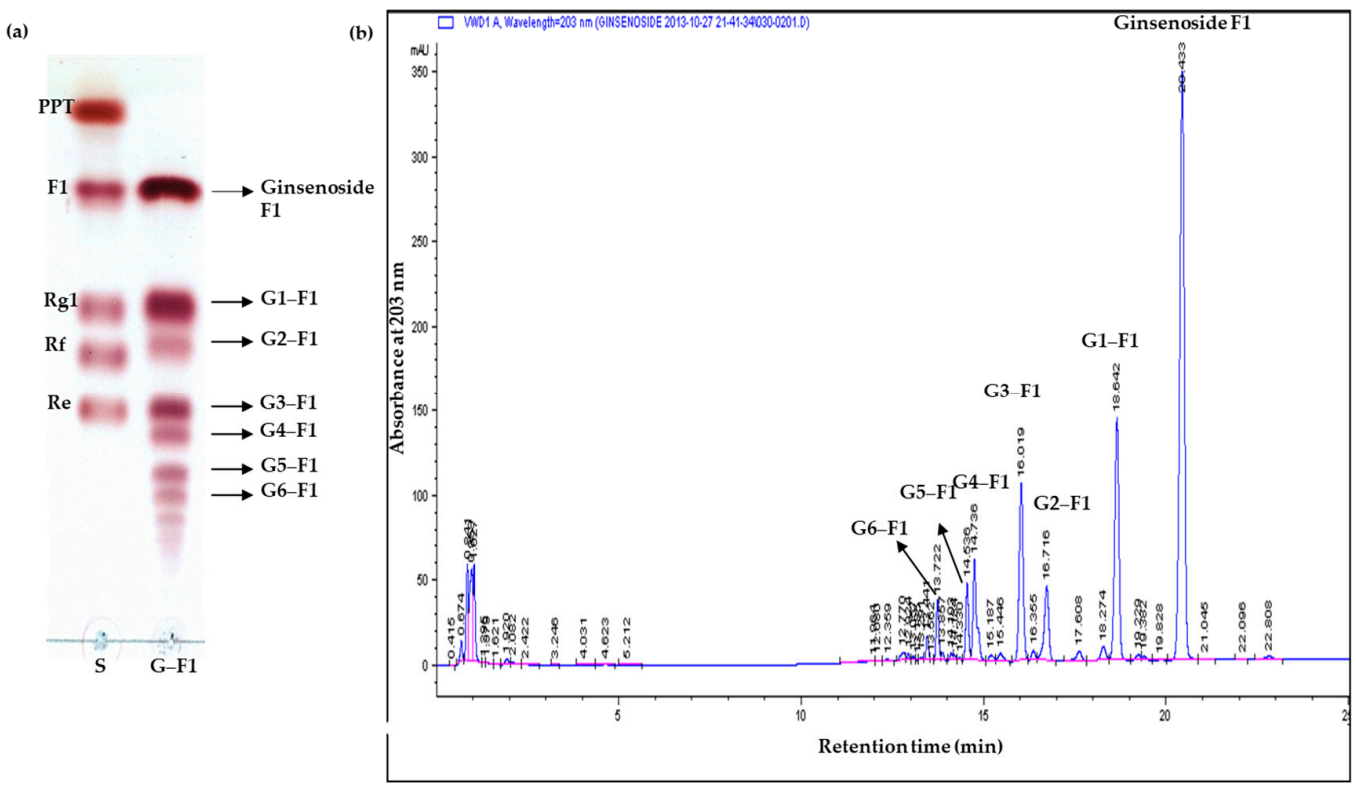

Figure 1. (a) Thin layer chromatography of new F1 glycosylated products after removal of excess sugar. (b) High-performance liquid chromatography (HPLC) analysis of F1 and various glycosylated products after reaction. G1-F1, compound 1; G2-F1, compound 2; G3-F1, compound 3; G4-F1, compound 4; G5-F1, compound 5; G6-F1, compound 6.

Compound 1 (G1-F1) was obtained as a white powder. The molecular formula of G1-F1 was determined to be $\mathrm{C}_{42} \mathrm{H}_{72} \mathrm{O}_{14}$ from the pseudomolecule ion peak $m / z$ 799.4843 [M-H] $]^{-}$in negative high-resolution fast atom bombardment-mass spectrometry (FAB-MS). The infrared spectrum showed strong absorbance from hydroxyl groups $\left(3366 \mathrm{~cm}^{-1}\right)$ and a double bond $\left(1650 \mathrm{~cm}^{-1}\right)$ in $\mathrm{G} 1-\mathrm{F} 1$ (Figure S4). In the ${ }^{1} \mathrm{H}$ NMR spectrum, proton signals of one olefin methine $\left(\delta_{\mathrm{H}} 5.30, \mathrm{dd}, J=6.0\right.$, $6.4 \mathrm{~Hz}, \mathrm{H}-24)$, three oxygenated methines $\left(\delta_{\mathrm{H}} 3.48, \mathrm{H}-3 ; 4.10, \mathrm{H}-12 ; 4.38, \mathrm{H}-6\right)$, and eight singlet methyls $\left(\delta_{\mathrm{H}} 1.98(\mathrm{H}-28), 1.58\right.$ (H-26), 1.56 (H-27), 1.55 (H-21), 1.45 (H-29), 1.08 (H-18), 1.01 (H-19), 0.98 (H-30)) were observed, indicating that G1-F1 has a protopanaxatriol-type triterpene moiety. Proton signals due to the sugar moiety, two anomeric proton signals at $\delta_{\mathrm{H}} 5.81\left(\mathrm{~d}, J=3.6 \mathrm{~Hz}, \mathrm{H}-1^{\prime \prime}\right)$ and $5.04(\mathrm{~d}$, $J=8.0 \mathrm{~Hz}, \mathrm{H}-1^{\prime}$ ), and several oxygenated methines and methylene proton signals at $\delta_{\mathrm{H}} 3.72 \sim 4.56$ were observed (Figure S5a). The ${ }^{13} \mathrm{C}$ NMR spectrum of G1-F1 (Figure S5b) exhibited 42 carbon signals due to a triterpene with two hexoses. An olefin quaternary carbon signal at $\delta_{C} 131.0(\mathrm{C}-25)$, one olefin methine carbon signal at $\delta_{C} 125.9$ (C-24), one oxygenated quaternary carbon signal at 83.5 (C-20), three 
oxygenated methine carbon signals $\left(\delta_{\mathrm{C}} 78.6(\mathrm{C}-3), 67.8(\mathrm{C}-6), 70.2(\mathrm{C}-12)\right)$, and eight methyl carbon signals $\left(\delta_{C} 32.0(C-28), 25.7\right.$ (C-26), 22.3 (C-21), 17.8 (C-18), 17.6 (C-19), 17.5 (C-27, 30), 16.3 (C-29)) were observed for the protopanaxatriol-type aglycone moiety. The chemical shifts of the sugar moieties signal $\left(\delta_{C} 98.1\left(\mathrm{C}-1^{\prime}\right), 81.2\left(\mathrm{C}-2^{\prime}\right), 78.5\left(\mathrm{C}-3^{\prime}\right), 76.6\left(\mathrm{C}-5^{\prime}\right), 75.5\left(\mathrm{C}-4^{\prime}\right), 62.1\left(\mathrm{C}-6^{\prime}\right)\right)$ suggested the presence of a glucopyranoside. The coupling constant of the anomeric proton signal $\left(\delta_{\mathrm{H}} 5.04, \mathrm{H}-1^{\prime}\right)$ was $8.0 \mathrm{~Hz}$, confirming $\beta$-D-glucopyranoside. Another sugar moiety $\left(\delta_{\mathrm{C}} 103.0\left(\mathrm{C}-1^{\prime \prime}\right), 75.2\left(\mathrm{C}-3^{\prime \prime}\right), 74.6\left(\mathrm{C}-2^{\prime \prime}\right)\right.$, $74.4\left(\mathrm{C}-5^{\prime \prime}\right), 71.9\left(\mathrm{C}-4^{\prime \prime}\right), 62.8\left(\mathrm{C}-6^{\prime \prime}\right)$ suggested the presence of glucopyranoside; the coupling constant of the anomeric proton signal $\left(\delta_{\mathrm{H}} 5.81, \mathrm{H}-1^{\prime \prime}\right)$ was $3.6 \mathrm{~Hz}$, confirming that the glucopyranose had a $\alpha$-glucosidic linkage. The connection between the $\beta$ - $D$-glucopyranosyl unit $\left(C-1^{\prime}\right)$ and the $C-20$ of the aglycone and that of another $\alpha$-D-glucopyranosyl unit $\left(C-1^{\prime \prime}\right)$ with $C-2^{\prime}$ of the inner glucose was verified by the cross-peaks observed between the anomer proton signal at $\delta_{\mathrm{H}} 5.04\left(\mathrm{H}-1^{\prime}\right)$ and the oxygenated quaternary carbon signal at $\delta_{\mathrm{C}} 83.5(\mathrm{C}-20)$ and between the anomer proton signal at $\delta_{\mathrm{H}} 5.81\left(\mathrm{H}-1^{\prime \prime}\right)$ and the oxygenated methine carbon signal at $\delta_{C} 81.2\left(C-2^{\prime}\right)$ in the HMBC spectrum, respectively (Figure $\mathrm{S} 5 \mathrm{c}, \mathrm{d})$. This was confirmed by the downfield shifts of the carbon $\left(\delta_{\mathrm{C}} 78.5\left(\mathrm{C}-3^{\prime}\right)\right)$ and proton signals $\left(\delta_{\mathrm{H}} 4.53\left(\mathrm{H}-3^{\prime}\right)\right)$ due to the glycosylation effect. Ultimately, the structure of G1-F1 was determined to be (20S)-3 $\beta, 6 \alpha, 12 \beta$-trihydroxydammar-24-ene-(20-O- $\beta$ - $D$-glucopyranosyl-( $1 \rightarrow 2)-\alpha$ - $D$-glucopyranoside), which has not been reported previously (Figure 2).

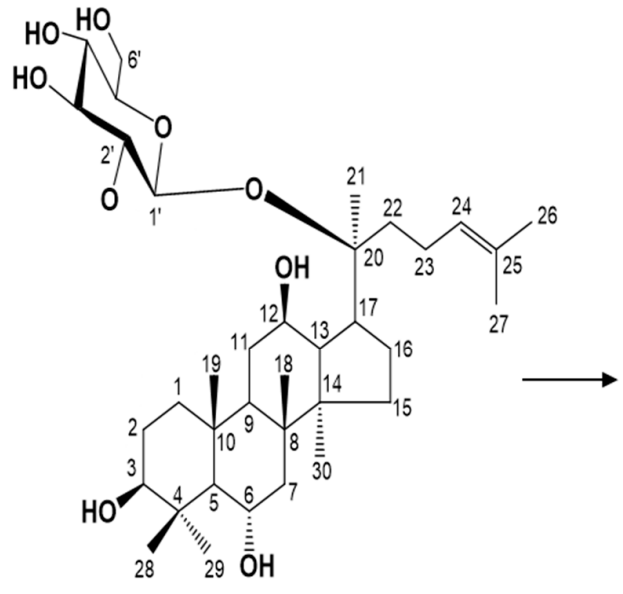

GinsenosideF1

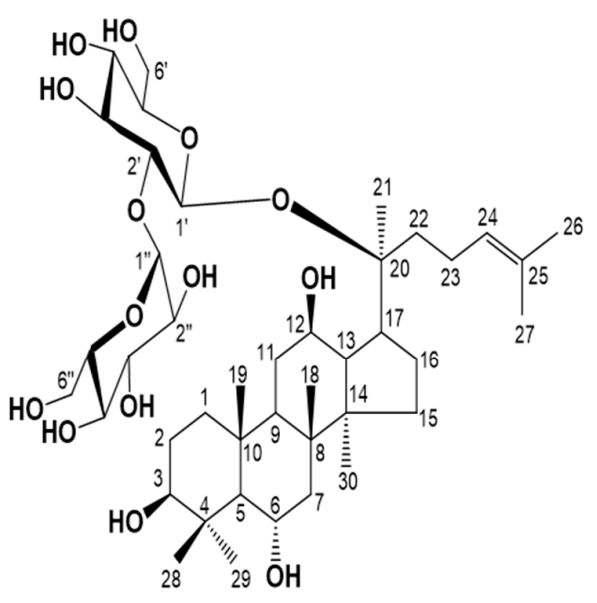

G1-F1

Figure 2. Chemical structures of ginsenoside F1 and its $\alpha$-glycosylated F1 (G1-F1).

\subsection{Characterization of Novel $\alpha$-Glycosylated Ginsenoside F1}

Water Solubility of Ginsenoside F1 and Novel $\alpha$-Glycosylated Ginsenoside F1

Transglycosylation reactions catalyzed by CGTase are an efficient method to enhance the water solubility of various compounds $[16,18,28]$. Accordingly, the water solubility of $\alpha$-glycosylated ginsenoside F1 was higher than that of F1 alone (data not shown). The soluble $\alpha$-glycosylated ginsenoside F1 should not only facilitate investigation of the pharmacological activities of ginsenoside F1, but also may be useful as a cosmetics ingredient.

\subsection{Cell Cytotoxicity}

3.5.1. Comparison of Cell Viability of Ginsenoside F1 and Novel $\alpha$-Glycosylated Ginsenoside F1 in Human Dermal Fibroblast Cells

To evaluate the effects of $\alpha$-glycosylated ginsenoside F1 and ginsenoside F1 on the cell viability of $\mathrm{HDFs}$, the cells were treated with different concentrations. Ginsenoside F1 reduced the cell viability of HDFs to a greater extent than $\alpha$-glycosylated ginsenoside F1 (G1-F1) in a dose-dependent manner 
(Figure 3). The $\alpha$-glycosylated ginsenoside F1 showed lower toxicity toward HDFs than ginsenoside F1 up to a concentration of $5 \mathrm{mg} / \mathrm{mL}$. The cell viability was greater than $90 \%$ of that of the control cells up to $2 \mathrm{mg} / \mathrm{mL}$. These results showed that ginsenoside F1 and $\alpha$-glycosylated ginsenoside F1 have no significant cytotoxicity against skin cells. Thus, the inhibitory effect of these compounds on collagenase expression was not due to cytotoxicity of these compounds at concentrations up to $2 \mathrm{mg} / \mathrm{mL}$.

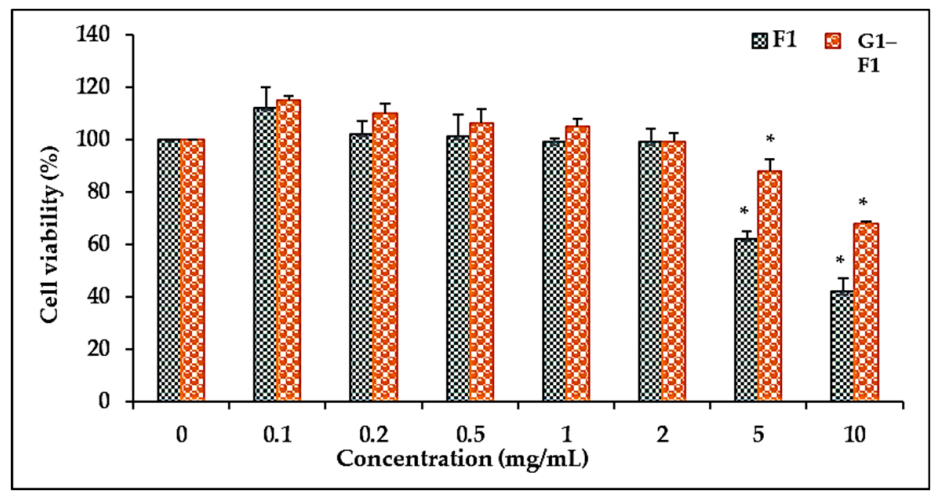

Figure 3. Cytotoxicity of ginsenoside F1 and $\alpha$-glycosylated ginsenoside F1 in human dermal fibroblast cells. Cells were preincubated with or without compounds for $24 \mathrm{~h}$, and cell viability was evaluated by 3-(4,5-dimethylthiazol-2-yl)-2,5-diphenyltetrazolium bromide (MTT) assay. Data represent the mean $\pm \mathrm{SD}$ (standard deviation) of triplicate experiments. ${ }^{*} p<0.05$ compared with the control. F1: ginsenoside F1; G1-F1: $\alpha$-glycosylated ginsenoside F1.

\subsubsection{Inhibition of Tyrosinase Activity by Ginsenoside F1 and G1-F1}

To investigate the tyrosinase inhibitory activity of G1-F1, the half maximal inhibitory concentration (IC50) values against mushroom tyrosinase were measured. The tyrosinase inhibitory activity of $\alpha$-glycosylated ginsenoside F1 was higher than that of ginsenoside F1 but weaker than that of arbutin (Figure 4).

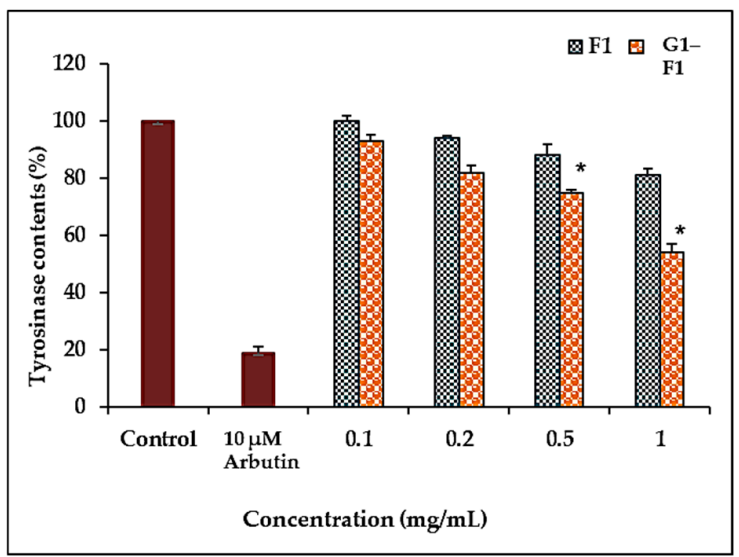

Figure 4. Inhibitory effects of ginsenoside F1 and $\alpha$-glycosylated ginsenoside F1 on Mushroon tyrosinase activity. Tyrosinase activity was measured using $3.3 \mathrm{mM}$ L-DOPA as a substrate. Results are expressed as the percentage of inhibition by ginsenoside F1 and $\alpha$-glycosylated compound. Arbutin was used as a positive control. Data represent the mean $\pm \mathrm{SD}$ of triplicate experiments. ${ }^{*} p<0.05$ compared with the control. F1: ginsenoside F1; G1-F1: $\alpha$-glycosylated ginsenoside F1.

It was previously reported that F1 can function as an anti-aging and antioxidant agent [11] and as a drug against skin cancer with antiproliferation and whitening functions [10]. Comparison of the inhibition of tyrosinase activity showed that $\alpha$-glycosylated ginsenoside F1 had a greater inhibitory 
effect on tyrosinase activity than ginsenoside F1, indicating that $\alpha$-glycosylated ginsenoside F1 might be an efficacious anti-tyrosinase agent for use in cosmetics.

3.5.3. Inhibition of Ultraviolet A (UVA)-Induced Matrix Metalloproteinase- (MMP-1) Expression of Ginsenoside F1 and G1-F1

Skin aging occurs as a result of collagen degradation through induction of MMPs by UV irradiation [29]. The $\alpha$-glycosylated ginsenoside F1 exhibited a greater inhibitory effect against collagenase (MMP-1) than the ginsenoside F1 after UVA irradiation of HDF cell lines (Figure 5), indicating that the C-3-hydroxyl group in the compounds is important for inhibitory activity. (-)-cis-3,3' , 4' ,5,5',7-Hexahydroxy-flavane-3-gallate (EGCG) was used as a positive control.

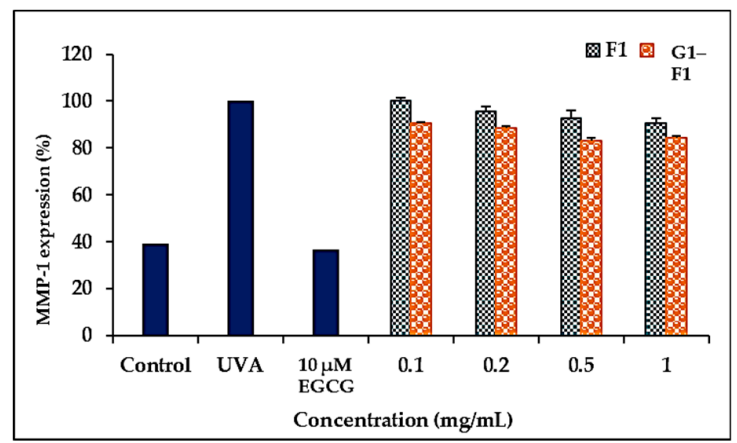

Figure 5. Inhibitory effects of ginsenoside F1 and $\alpha$-glycosylated ginsenoside F1 on the expression of MMP-1 in UVA-irradiated human dermal fibroblasts. The cells were cultured in the presence of ginsenoside F1 and $\alpha$-glycosylated ginsenoside F1 $(0-1 \mathrm{mg} / \mathrm{mL})$ for $24 \mathrm{~h}$ and subjected to ELISA. The results were expressed as the average $\pm \mathrm{SD}$ of triplicate determinations. ${ }^{*} p<0.05$ compared with UVA irradiation. F1: ginsenoside F1; G1-F1: $\alpha$-glycosylated ginsenoside F1.

In addition to the number of sugars, their linkage positions and alpha vs. beta linkages affect pharmacological activities. For example, ginsenoside F1 and Rh1 have the same number of sugar moieties and the same molecular weight but different glucose attachment positions at C-20 and C-6, respectively. F1 showed significantly greater inhibition of viability than Rh1 in prostate cancer cell lines [30]. The glycosylation and nano formulations of ginseng saponins [13,25,26,31-33] and other steroidal saponins $[19,27]$ has recently attracted increased interest.

The alpha isomers of glucose also exhibited significant activity, especially stronger inhibitory activity of $\alpha$-arbutin on tyrosinase compared with $\beta$-arbutin [22]. Similarly, in comparison with the common beta isomers of glucose in ginsenosides, $\alpha$-glycosyl ginsenoside was reported to have a reduced bitter taste [26], suggesting its potential as an additive in food products.

\section{Conclusions}

This study describes for the first time the glycosylation of ginsenoside F1 by CGTase and identification of a novel $\alpha$-glucosylated F1 with an unusual $\alpha$ - $D$-glcp- $(1 \rightarrow 2)-\beta$ - $D$-glcp sugar chain (G1-F1). The novel compound G1-F1 showed lower cytotoxicity and stronger inhibitory activity against tyrosinase and collagenase (MMP-1) than ginsenoside F1. This novel G1-F1 may be a potential pharmacological active compound. A single $\alpha$-glucosylated F1 was purified in this study, and other new glycosylated spots remain to be characterized. 
Supplementary Materials: The following are available online at http://www.mdpi.com/2218-273X/8/4/142/s1. Figure S1: TLC analysis of transglycosylation of minor ginsenosides (Rh2, CK, PPD, Rh1, F1, PPT). S, standard; (i) Each ginsenoside with CGTase only and (ii) Each ginsenoside with CGTase and dextrin, Figure S2. (a). Effect of dextrin on transglycosylation of ginsenoside F1. Toruzyme ${ }^{\circledR}(20 \mu \mathrm{L})$ was incubated with ginsenoside F1 (1 mg) in $1 \mathrm{~mL}$ of $20 \mathrm{mM}$ sodium phosphate buffer at $60 \pm 1^{\circ} \mathrm{C}$ for $2 \mathrm{~h}$, (b). Effect of Toruzyme ${ }^{\circledR}$ on transglycosylation of ginsenoside F1. Toruzyme ${ }^{\circledR}(5-30 \mu \mathrm{L})$ was incubated with ginsenoside F1 $(1 \mathrm{mg})$ and dextrin $(5 \mathrm{mg})$ in $1 \mathrm{~mL}$ of $20 \mathrm{mM}$ sodium phosphate buffer at $60 \pm 1^{\circ} \mathrm{C}$ for $2 \mathrm{~h}$. The yield was calculated as the increase in product by HPLC, Figure S3: TLC analysis of transglycosylation of ginsenoside F1 with Toruzyme ${ }^{\circledR}$ and dextrin at different times (min). S, standard of higher molecular weight ginsenosides than F1 in the same protopanaxatriol type ginsenosides; F1+toru (Control 1): Ginsenoside F1 and CGTase Toruzyme enzyme alone; Dextrin+toru (Control 2): Dextrin (sugar donor) and CGTase Toruzyme enzyme alone, Figure S4. (a). Infrared spectrum (FTIR) of novel $\alpha$-glycosylated ginsenoside F1 (G1-F1), Figure S5. (a). ${ }^{1} \mathrm{H}$-NMR spectrum of novel $\alpha$-glycosylated ginsenoside F1 (G1-F1). (b). ${ }^{13}$ C-NMR spectrum of novel $\alpha$-glycosylated ginsenoside F1 (G1-F1). (c). gHSQC spectrum of novel $\alpha$-glycosylated ginsenoside F1 (G1-F1). (d). Key gHMBC spectrum of novel $\alpha$-glycosylated ginsenoside F1 (G1-F1).

Author Contributions: Conceptualization-H.J.L. and R.M.; Methodology-S.S.M., H.J.L., and J.W.M.; Validation-D.Y.L., Resources-Y.J.K.; Writing—original draft preparation-S.S.M., and H.J.L.; Writing一review, and editing-R.M. and Z.J.; Funding Acquisition-D.U.Y. and D.C.Y.; Project Administration and Supervision-D.C.Y.

Funding: This research received no external funding.

Acknowledgments: This research was supported by a grant from the Korea Institute of Planning \& Evaluation for Technology in Food, Agriculture, Forestry, \& Fisheries (KIPET NO: 317007-3), Republic of Korea.

Conflicts of Interest: The authors declare no conflicts of interest. The funders had no role in the design of the study; in the collection, analyses, or interpretation of data; in the writing of the manuscript; or in the decision to publish the results.

\section{References}

1. Wong, A.S.; Che, C.M.; Leung, K.W. Recent advances in ginseng as cancer therapeutics: A functional and mechanistic overview. Nat. Prod. Rep. 2015, 32, 256-272. [CrossRef] [PubMed]

2. Mathiyalagan, R.; Subramaniyam, S.; Kim, Y.J.; Kim, Y.C.; Yang, D.C. Ginsenoside compound K-bearing glycol chitosan conjugates: Synthesis, physicochemical characterization, and in vitro biological studies. Carbohydr. Polym. 2014, 112, 359-366. [CrossRef] [PubMed]

3. Ahn, S.; Siddiqi, M.H.; Noh, H.-Y.; Kim, Y.-J.; Kim, Y.-J.; Jin, C.-G.; Yang, D.-C. Anti-inflammatory activity of ginsenosides in LPS-stimulated RAW 264.7 cells. Sci. Bull. 2015, 60, 773-784. [CrossRef]

4. Wee, J.J.; Mee Park, K.; Chung, A.S. Biological activities of ginseng and its application to human health. In Herbal Medicine: Biomolecular and Clinical Aspects, 2nd ed.; Benzie, I.F.F., Wachtel-Galor, S., Eds.; CRC Press: Boca Raton, FL, USA, 2011.

5. Sathishkumar, N.; Sathiyamoorthy, S.; Ramya, M.; Yang, D.U.; Lee, H.N.; Yang, D.C. Molecular docking studies of anti-apoptotic BCL-2, BCL-XL, and MCL-1 proteins with ginsenosides from Panax ginseng. J. Enzyme Inhib. Med. Chem. 2012, 27, 685-692. [CrossRef] [PubMed]

6. Yang, W.Z.; Hu, Y.; Wu, W.Y.; Ye, M.; Guo, D.A. Saponins in the genus Panax L. (Araliaceae): A systematic review of their chemical diversity. Phytochemistry 2014, 106, 7-24. [CrossRef] [PubMed]

7. Wakabayashi, C.; Murakami, K.; Hasegawa, H.; Murata, J.; Saiki, I. An intestinal bacterial metabolite of ginseng protopanaxadiol saponins has the ability to induce apoptosis in tumor cells. Biochem. Biophys. Res. Commun. 1998, 246, 725-730. [CrossRef] [PubMed]

8. Tawab, M.A.; Bahr, U.; Karas, M.; Wurglics, M.; Schubert-Zsilavecz, M. Degradation of ginsenosides in humans after oral administration. Drug Metab. Dispos. 2003, 31, 1065-1071. [CrossRef] [PubMed]

9. Han, J.; Lee, E.; Kim, E.; Yeom, M.H.; Kwon, O.; Yoon, T.H.; Lee, T.R.; Kim, K. Role of epidermal $\gamma \delta$ T-cell-derived interleukin 13 in the skin-whitening effect of Ginsenoside F1. Exp. Dermatol. 2014, 23, 860-862. [CrossRef] [PubMed]

10. Yoo, D.S.; Rho, H.S.; Lee, Y.G.; Yeom, M.H.; Kim, D.H.; Lee, S.-J.; Hong, S.; Lee, J.; Cho, J.Y. Ginsenoside F1 modulates cellular responses of skin melanoma cells. J. Ginseng Res. 2011, 35, 86-91. [CrossRef]

11. Lee, E.H.; Cho, S.Y.; Kim, S.J.; Shin, E.S.; Chang, H.K.; Kim, D.H.; Yeom, M.H.; Woe, K.S.; Lee, J.; Sim, Y.C.; et al. Ginsenoside F1 protects human HaCaT keratinocytes from ultraviolet-B-induced apoptosis by maintaining constant levels of Bcl-2. J. Investig. Dermatol. 2003, 121, 607-613. [CrossRef] [PubMed] 
12. Shibuya, M.; Nishimura, K.; Yasuyama, N.; Ebizuka, Y. Identification and characterization of glycosyltransferases involved in the biosynthesis of soyasaponin I in Glycine max. FEBS Lett. 2010, 584, 2258-2264. [CrossRef] [PubMed]

13. Mathiyalagan, R.; Kim, Y.-H.; Kim, Y.; Kim, M.-K.; Kim, M.-J.; Yang, D. Enzymatic Formation of Novel Ginsenoside Rg1- $\alpha$-Glucosides by Rat Intestinal Homogenates. Appl. Biochem. Biotechnol. 2015, 177, 1701-1715. [CrossRef] [PubMed]

14. Nakano, H.; Kiso, T.; Okamoto, K.; Tomita, T.; Manan, M.B.; Kitahata, S. Synthesis of glycosyl glycerol by cyclodextrin glucanotransferases. J. Biosci. Bioeng. 2003, 95, 583-588. [CrossRef]

15. Li, S.; Li, W.; Xiao, Q.Y.; Xia, Y. Transglycosylation of stevioside to improve the edulcorant quality by lower substitution using cornstarch hydrolyzate and CGTase. Food Chem. 2013, 138, 2064-2069. [CrossRef] [PubMed]

16. Kometani, T.; Terada, Y.; Nishimura, T.; Takii, H.; Okada, S. Transglycosylation to hesperidin by cyclodextrin glucanotransferase from an alkalophilic Bacillus species in alkaline $\mathrm{pH}$ and properties of hesperidin glycosides. Biosci. Biotechnol. Biochem. 1994, 58, 1990-1994. [CrossRef]

17. Kamaruddin, K.; Illias, R.M.; Aziz, S.A.; Said, M.; Hassan, O. Effects of buffer properties on cyclodextrin glucanotransferase reactions and cyclodextrin production from raw sago (Cycas revoluta) starch. Biotechnol. Appl. Biochem. 2005, 41, 117-125. [PubMed]

18. Suzuki, Y.; Suzuki, K. Enzymatic formation of 4G- $\alpha-D$-glucopyranosyl-rutin. Agric. Biol. Chem. 1991, 55, 181-187. [CrossRef] [PubMed]

19. Wang, Y.Z.; Feng, B.; Huang, H.Z.; Kang, L.P.; Cong, Y.; Zhou, W.B.; Zou, P.; Cong, Y.W.; Song, X.B.; Ma, B.P. Glucosylation of steroidal saponins by cyclodextrin glucanotransferase. Planta Med. 2010, 76, 1724-1731. [CrossRef] [PubMed]

20. Uchida, K.; Suzuki, Y. Enzymatic synthesis of a new derivative of thiamin, O- $\alpha$-glucosylthiamin. Biosci. Biotechnol. Biochem. 1998, 62, 221-224. [CrossRef] [PubMed]

21. Seo, D.H.; Jung, J.H.; Ha, S.J.; Cho, H.K.; Jung, D.H.; Kim, T.J.; Baek, N.I.; Yoo, S.H.; Park, C.S. High-yield enzymatic bioconversion of hydroquinone to $\alpha$-arbutin, a powerful skin lightening agent, by amylosucrase. Appl. Microbiol. Biotechnol. 2012, 94, 1189-1197. [CrossRef] [PubMed]

22. Sugimoto, K.; Nishimura, T.; Nomura, K.; Sugimoto, K.; Kuriki, T. Syntheses of arbutin- $\alpha$-glycosides and a comparison of their inhibitory effects with those of $\alpha$-arbutin and arbutin on human tyrosinase. Chem. Pharm. Bull. 2003, 51, 798-801. [CrossRef] [PubMed]

23. Quan, L.H.; Min, J.W.; Sathiyamoorthy, S.; Yang, D.U.; Kim, Y.J.; Yang, D.C. Biotransformation of ginsenosides Re and Rg1 into ginsenosides Rg2 and Rh1 by recombinant $\beta$-glucosidase. Biotechnol. Lett. 2012, 34, 913-917. [CrossRef] [PubMed]

24. Sim, G.-S.; Lee, B.-C.; Cho, H.; Lee, J.; Kim, J.-H.; Lee, D.-H.; Kim, J.-H.; Pyo, H.-B.; Moon, D.; Oh, K.-W.; et al. Structure activity relationship of antioxidative property of flavonoids and inhibitory effect on matrix metalloproteinase activity in UVA-irradiated human dermal fibroblast. Arch. Pharm. Res. 2007, 30, 290-298. [CrossRef] [PubMed]

25. Kim, M.J.; Kim, Y.H.; Song, G.S.; Suzuki, Y.; Kim, M.K. Enzymatic transglycosylation of ginsenoside Rg1 by rice seed $\alpha$-glucosidase. Biosci. Biotechnol. Biochem. 2016, 80, 318-328. [CrossRef] [PubMed]

26. Kim, Y.H.; Lee, Y.G.; Choi, K.J.; Uchida, K.; Suzuki, Y. Transglycosylation to ginseng saponins by cyclomaltodextrin glucanotransferases. Biosci. Biotechnol. Biochem. 2001, 65, 875-883. [CrossRef] [PubMed]

27. Zhou, W.B.; Feng, B.; Huang, H.Z.; Qin, Y.J.; Wang, Y.Z.; Kang, L.P.; Zhao, Y.; Wang, X.N.; Cai, Y.; Tan, D.W.; et al. Enzymatic synthesis of $\alpha$-glucosyl-timosaponin BII catalyzed by the extremely thermophilic enzyme: Toruzyme 3.0L. Carbohydr. Res. 2010, 345, 1752-1759. [CrossRef] [PubMed]

28. Sato, T.; Nakagawa, H.; Kurosu, J.; Yoshida, K.; Tsugane, T.; Shimura, S.; Kirimura, K.; Kino, K.; Usami, S. $\alpha$-anomer-selective glucosylation of (+)-catechin by the crude enzyme, showing glucosyl transfer activity, of Xanthomonas campestris WU-9701. J. Biosci. Bioeng. 2000, 90, 625-630. [CrossRef]

29. Kligman, A.M. Early destructive effect of sunlight on human skin. JAMA 1969, 210, 2377-2380. [CrossRef] [PubMed] 
30. Li, W.; Liu, Y.; Zhang, J.W.; Ai, C.Z.; Xiang, N.; Liu, H.X.; Yang, L. Anti-androgen-independent prostate cancer effects of ginsenoside metabolites in vitro: Mechanism and possible structure-activity relationship investigation. Arch. Pharm. Res. 2009, 32, 49-57. [CrossRef] [PubMed]

31. Luo, S.L.; Dang, L.Z.; Zhang, K.Q.; Liang, L.M.; Li, G.H. Cloning and heterologous expression of UDP-glycosyltransferase genes from Bacillus subtilis and its application in the glycosylation of ginsenoside Rh1. Lett. Appl. Microbiol. 2015, 60, 72-78. [CrossRef] [PubMed]

32. Wang, D.D.; Jin, Y.; Wang, C.; Kim, Y.J.; Perez, Z.E.J.; Baek, N.I.; Mathiyalagan, R.; Markus, J.; Yang, D.C. Rare ginsenoside Ia synthesized from F1 by cloning and overexpression of the UDP-glycosyltransferase gene from Bacillus subtilis: Synthesis, characterization, and in vitro melanogenesis inhibition activity in BL6B16 cells. J. Ginseng Res. 2018, 42, 42-49. [CrossRef] [PubMed]

33. Mathiyalagan, R.; Yang, D.C. Ginseng nanoparticles: A budding tool for cancer treatment. Nanomedicine 2017, 12, 1091-1094. [CrossRef] [PubMed]

(C) 2018 by the authors. Licensee MDPI, Basel, Switzerland. This article is an open access article distributed under the terms and conditions of the Creative Commons Attribution (CC BY) license (http://creativecommons.org/licenses/by/4.0/). 